touch with the on ground staff in COVID facility for any escalations and condition of the patient. Step 5: Particular time slot was fixed for family briefing daily by the treating doctor.

Impact The impact has been multi-layered where certain changes did show an instant effect to its full magnitude. Patient Satisfaction Score increased from 92\% to 96\%.Appreciations from Patients and Family Members on different platforms like Google reviews, twitter and software for patient satisfaction.

\section{A COMPARATIVE ANALYSIS OF JUNIOR DOCTOR REDEPLOYMENT STRATEGIES DURING THE COVID-19 WAVES 2020-2021 - RCP CHIEF REGISTRARS EXPERIENCE}

${ }^{1}$ Shalini Rajcoomar, ${ }^{2}$ Jonathan Downing, ${ }^{3}$ Jalpa Kotecha, ${ }^{4}$ Rebecca Thom ${ }^{5}$ Chirag Pate ${ }^{6}$ Joseph Hetherington, ${ }^{7}$ Bevin McCartan, ${ }^{8}$ Georgina Barrows, ${ }^{9}$ Courteney Mathewson. ${ }^{1} R C P$ Chief Registrar, Great Western Hospital NHS trust, UK; ${ }^{2} R C P$ Chief Registrar, Royal United Hospital Bath, UK; ${ }^{3} R C P$ Chief Registrar, Epsom and St Helier University Hospitals NHS Trust, UK; ${ }^{4} R C P$ Chief Registrar, Kings College Hospital, UK; ${ }^{5} R C P$ Chief Registrar, University College London Hospitals, UK; ${ }^{6} R C P$ Chief Registrar, Croydon Health Services, UK; ${ }^{7} R C P$ Chief Registrar, University College Hospital London, UK; ${ }^{8} R C P$ Chief Registrar, Nottingham University Hospitals NHS Trust, UK; ${ }^{9}$ RCP Chief Registrar, North Bristol NHS Trust, UK

10.1136/leader-2021-FMLM.4

Aim Large scale workforce redeployment was common during the Covid-19 pandemic, with junior doctors significantly affected. Royal College of Physician Chief Registrars helped facilitate redeployment and were affected themselves. They were able to compare strategies and leadership approaches between waves and different trusts.

Method Chief Registrars discussed their experiences during online discussions, collecting quantitative and qualitative data on a shared online template, with their Trust's consent. Data collected included number and grade of junior doctors affected, leadership strategies and feedback.

Result Complete quantitative data for both waves were available from 4 trusts, and partial from 7 trusts. 8 District General and 6 Tertiary/Teaching hospitals were represented.

Mean length of redeployment in wave 1 was longer (10.4 weeks [range 6.5-20]), compared to 6.2 weeks [range 0-10], with more doctors redeployed (mean 167 [range 40-259] compared with 42 doctors [range 0-86], despite higher numbers of Covid inpatients during wave 2. 1 trust implemented changes to working patterns instead of staff redeployment. Higher proportions of Foundation Doctors were redeployed in wave $2(42 \%)$ compared to wave $1(30 \%)$, with Core and GP trainees relative sparing ( $26 \%$ vs $12 \%)$.

All trusts reported clinical representation in organising and communicating redeployment decisions, and all but one involved Chief Registrar. There was wide variation in stakeholder involvement, with no correlation to hospital size.

Junior doctors reported feeling valued with a sense of team during redeployment. Feedback reported from wave 2 was less positive; shorter redeployment, frequent work pattern changes, suboptimal communication and burnout.

Conclusion A more nuanced approach to redeployment was taken in 2021 compared to 2020. Clinical involvement in redeployment decisions, improving communication and collecting feedback of those involved, should be priorities during any future redeployment.

\section{A FELLOWSHIP FOR THE FUTURE: ONE TRAINEE'S UNIQUE EXPERIENCE OF A LEADERSHIP AND TRANSFORMATION FELLOWSHIP ENCOMPASSING PRIVATE SECTOR AND NHS EXPERIENCE}

Leonora Bowen. The Royal Marsden Hospital, The Central London School of Anaesthesia, UK

10.1136/leader-2021-FMLM.5

In order to better understand how to be an effective leader, in August 2019 I embarked on a Leadership and Transformation Fellowship. It comprised of a year long secondment to the management consultancy health team at Deloitte LLP, followed by nine months as an Anaesthetic Transformation Fellow at Croydon Health Services NHS Trust, (with changes to timings to accommodate the pandemic). I was especially interested to learn how management consultancy intersects with our own quality improvement endeavours as clinicians.

Management Consultancy

I gained skills working on a range of projects which included: the transformation strategy of two acute NHS hospital trusts; clinical workforce redesign and service options appraisal at an Arms' Length NHS body; and national pandemic support.

Anaesthetic Transformation Fellow

I led a multidisciplinary project to create a Surgical Enhanced Care Unit (SECU) which provides post operative care for high risk elective surgery in a Covid protected setting whilst our critical care was unavailable. In the last year SECU has safely treated 129 patient. I also engaged in hospital-wide and departmental projects.

Lessons Learnt

- Transformation in the NHS is possible; whilst the pandemic has been disruptive it has revealed opportunities for dynamic change by motivated leaders.

- Effective change is best achieved when stakeholders are involved in a collaborative fashion, improving the likelihood of a meaningful impact.

- Building relationships is key, and can be challenging for a rotating trainee.

This Fellowship provided me with a unique opportunity to encounter a comprehensive range of healthcare leadership, from private sector and central NHS bodies, to trainee led projects. The experience has been invaluable, and I would highly recommend supporting trainees in leadership, as the benefits to the NHS would be innumerable.

My Fellowship was funded by Health Education England, the Royal College of Anaesthetists and Deloitte LLP.

\begin{tabular}{l}
\hline 6 \\
A QIP TO ADDRESS PATIENT-CENTRED CARE BY \\
INCREASING THE DISTRIBUTION OF PATIENT \\
INFORMATION LEAFLETS (PILS) BY 10\%, AT THE POINT \\
OF PATIENT DISCHARGE AT PILGRIM HOSPITAL ED, BY \\
MARCH 2021
\end{tabular}

1,2Zahid Yusuf*, ${ }^{2}$ Lisa Bateman, ${ }^{2}$ Rajeshwar Ranganathan. ${ }^{1}$ Institute of Continuing Education, University of Cambridge, UK; ${ }^{2}$ Department of Emergency Medicine, Pilgrim Hospital, Boston, UK

\subsection{6/leader-2021-FMLM.6}

Background Patients discharged from ED should be provided with verbal and written discharge advice $(1,2)$. Patients 